\title{
Pengembangan Sistem Informasi Data KB dan Analisis Pola Pemilihan Metode Kontrasepsi Menggunakan Algoritma Sql-Based Fp-Growth
}

\author{
Yumina Jumiati ${ }^{* 1)}$ dan Nurdin Bahtiar ${ }^{2)}$ \\ 1,2 Jurusan Ilmu komputer/Informatika, Fakultas Sains dan Matematika, Universitas Diponegoro, \\ Jl. Prof. H. Soedharto, SH, Tembalang, Semarang, 50275, Indonesia
}

\begin{abstract}
One of Unit Pelaksana Teknis Pemberdayaan Masyarakat, Perempuan, dan Keluarga Berencana (UPT BAPERMASPER dan KB) Region XV District of Mijen's duty is to lead, plan, do, evaluate, and report the data management in service, management, and control of family planning programs and the empowerment of women in the district. The inadequate number offield officers (PLKB) often become spectacle in collecting and reporting the data KB. Family Planning Data Information System (SIDAK) is developed in order to support the mentioned task to make it easier to report, store, and manage the data. Additionally, SIDAK is equipped with a data analysis feature with association mining technique using SQL-Based FP-Growth algorithm. This algorithm analyze the data KB and create a relation (association rule) between the attributes used for analysis; the wive's age, the highest education achieved by the couple, the number of children, the welfare level, and the contraception method. The research analysis of 302 dataKBs resulted in maximum support value of $1.66 \%$, maximum confidence value of $100 \%$, and maximum lift ratio of 60.24 .
\end{abstract}

Keywords:data mining, association rule, SQL-Based FP-Growth.

\section{Pendahuluan}

Unit Pelaksana Teknis Badan Pemberdayaan Masyarakat, Perempuan, dan Keluarga Berencana (UPT BAPERMASPER dan KB) Wilayah XV Kecamatan Mijen Semarang Jawa Tengah, bertugas memimpin, merencanakan, melaksanakan, mengevaluasi, dan melaporkan pengelolaan, sebagian fungsi Badan di bidang pelayanan, pengelolaan, dan pengendali program KB dan pemberdayaan perempuan di wilayah kecamatan tersebut. Dalam melaksanakan tugasnya, UPT tersebut dibantu oleh Petugas Penyuluh Keluarga Berencana Desa (PPKBD) pada setiap kelurahan yang melakukan pendataan keluarga dan melaporkan ke UPT secara manual. Data hasil pendataan kemudian dianalisis dan dievaluasi untuk menentukan kebijakan yang tepat pada pelaksanaan program KB yang akan dilaksanakan. Minimnya jumlah petugas lapangan sering menjadi kendala dalam hal pengumpulan dan pelaporan data.

Sistem pengelolaan berbasis komputer merupakan suatu hal yang penting dalam lembaga ini, kendala yang muncul merupakan tantangan tersendiri bagi pengelola agar menyediakan layanan sistem informasi yang akurat dan efisien. Suatu informasi dikatakan bernilai bila manfaatnya lebih efektif dibandingkan dengan biaya mendapatkannya (Yakub, 2012). Karenanya, perlu diupayakan pembangunan sistem informasi yang dapat memberikan manfaat lebih bagi penggunanya, misalnyadengan menambahkan teknik data mining untuk membantu dalam pembuatan keputusan.

Berdasarkan analisis yang dilakukan oleh Radita Kusumaningrum, beberapa faktor yang mempengaruhi pemilihan metode kontrasepsi oleh peserta KB di antaranya adalah umur istri, jumlah anak, kesejahteraan, kepemilikan JAMKESMAS, pendidikan, pengetahuan, dukungan

*Correspondance : yuminajumiati@gmail.com 
suami / istri, serta agama (Kusumaningrum, 2009).Tidak ada metode kontrasepsi yang aman dan efektif bagi semua klien karena masing-masing mempunya kesesuaian dan kecocokan individual. Secara umum persyaratan metode kontrasepsi ideal adalah: aman, berdaya guna, dapat diterima, harga terjangkau, serta mengembalikan kesuburan bila tidak lagi digunakan. (Nasution, 2011).

Berdasarkan permasalahan di atas, makalah ini akan membahas tentang bagaimana mengembangan teknik data mining asosiasi untuk membantu pengguna alat $\mathrm{KB}$ dalam membuat keputusan memilih metode kontrasepsi yang sesuai dengan karakteristik mereka.Dalam hal ini metode yang digunakan adalah algoritma SQL-Based FP-Growth.

\section{Metode Penelitian}

\section{Data Mining}

Menurut Jiawei Han dan Micheline Kamber (2006), data mining adalah kegiatan menemukan pola yang menarik dari data dalam jumlah yang sangat besar. Sumber data dapat berupa basis data, gudang data (data warehouse), atau penyimpanan informasi lainnya.Data mining berkaitan dengan bidang ilmu-ilmu lain, seperti database system, data warehousing, statistics, machine learning, information retrieval, dan komputasi tingkat tinggi(Han \& Kamber, 2006).

Menurut Budi Santosa (2007), data mining(Knowledge Discovery in Database /KDD) adalah kegiatan yang meliputi pengumpulan, pemakaian data historis untuk menemukan keteraturan, pola atau hubungan dalam set data berukuran besar (Santosa B. , 2007)

Berdasarkan beberapa definisi di atas, maka dapat disimpulkan bahwa data mining adalah serangkaian proses penggalian sekumpulan besar data untuk menemukan aturan, pola atau hubungan menarik di dalamnya sebagai suatu pengetahuan lebih yang bermanfaat.

Tahapan data mining menurut Han dan Kamber (2006) adalah sebagai berikut:
a. Data Cleaning
b. Data Integration
c. Data Selection
d. Data Transformation
e. Data Mining
f. Pattern Evaluation
g. Knowledge Presentation

\section{Association Rule Mining (ARM)}

Menurut Kusrini dan Emha Taufik Luthfi (2009), ARM adalah teknik data mining untuk menemukan aturan asosiasi antara suatu kombinasi item. Interestingness measure yang dapat digunakan dalam data mining adalah support dan confidence. Support adalah suatu ukuran yang menunjukkan seberapa besar tingkat dominasi suatu item atau itemset dari keseluruhan transaksi. Confidence adalah suatu ukuran yang menunjukkan hubungan antar dua item secara conditional.Metodologi dasar analisis asosiasi terbagi menjadi dua tahap, yaitu tahap analisis pola frekuensi tinggi dan tahap pembentukan aturan asosiasi(Kusrini \& Luthfi, 2009).

\section{a. Analisis Pola Frekuensi Tinggi}

Tahapan mencari kombinasi item yang memenuhi syarat minimum dari nilai support dalam basis data. Nilai support sebuah item A diperoleh dengan rumus (1).

Support $(\mathrm{A})=\frac{\sum \text { transaksi mengandung } \mathrm{A}}{\sum \text { transaksi dalam database }}$ 
b. Pembentukan Aturan Asosiasi

Setelah semua pola frekuensi tinggi ditemukan, kemudian dicari aturan asosiasi yang memenuhi syarat minimum untuk confidence dengan menghitung confidence aturan asosiatif $\mathrm{A} \rightarrow \mathrm{B}$. Nilai confidence dari aturan $\mathrm{A} \rightarrow \mathrm{B}$ diperoleh dari rumus (2).

Confidence $=\frac{\sum \text { transaksi mengandung A dan } \mathrm{B}}{\sum \text { transaksi mengandung A }}$

Selain menggunakan confidence untuk mengukur tingkat kebenaran, dikenal juga lift ratio untuk melihat kuat tidaknya aturan asosiasi dengan membandingkan dengan nilai benchmark confidence. Dimana diasumsikan kejadian item dari consequent dalam suatu transaksi adalah independent dengan kejadian dari antecedent dari suatu asosiasi(Santosa B. , 2007)

Benchmark confidence $=\frac{\sum \text { transaksi dengan item dalam consequent }}{\sum \text { transaksi dalam database }}$

Lift ratioadalah perbandingan antara confidence untuk suatu aturan dibagi dengan benchmarkconfidence, dimana diasumsikan consequent dan antecedent saling independent. Nilai lift ratio lebih besar dari 1 menunjukkan adanya manfaat dari aturan tersebut. Lebih tinggi nilai lift ratio, lebih besar kekuatan asosiasi(Santosa B., 2007).

$$
\text { Lift Ratio }=\frac{\text { confidence }}{\text { benchmarkconfidence }}
$$

\section{SQL-Based FP-Growth}

Pembangunan FP-Tree pada algoritma FP-Growth pada suatu basis data yang besar memerlukan kapasitas memori yang sangat besar juga. Penelitian yang dilakukan oleh Xuequn Shang, Sattler Kai-Uwe, dan Geist Ingolf, menemukan suatu solusi permasalahan tersebut dengan memanfaatkan sistem manajemen basis data relasional (Relational Database Management System/RDBMS).

Salah satu alternatif adalah dengan menyimpan FP-Tree dalam struktur tabel (tabel FP).Terdapat dua pendekatan dalam pembangunan tabel FP, yaitu pendekatan pola frekuen (Frequent Pattern/FP) dan pendekatan dengan perluasan pola frekuen (Expand Frequent Pattern/EFP).Pendekatan FP memeriksa tiap item frekuen satu per satu, apakah sesuai atau tidak untuk dimasukkan ke dalam tabel FP. Pendekatan EFP membangun sebuah tabel FP-Tree temporer (tabel EFP), kemudian membangun tabel FP dari tabel EFP (Shang, 2005).

Tahapan algoritma SQL-Based FP-Growth dijelaskan sebagai berikut (Schuiling, 2014):

\section{a. Pembuatan Tabel FP}

Tabel FP merupakan bentuk penerapan FP-Tree dalam bentuk tabel. Pembuatan tabel FP yang dijelaskan pada tahapan ini mengikuti pendekatan FP, dilakukan dalam tiga tahap sebagai berikut:

(1.) Item counting (penghitungan item): memindai tabel transaksi satu kali dan hitung frekuensi kemunculan item (support count).

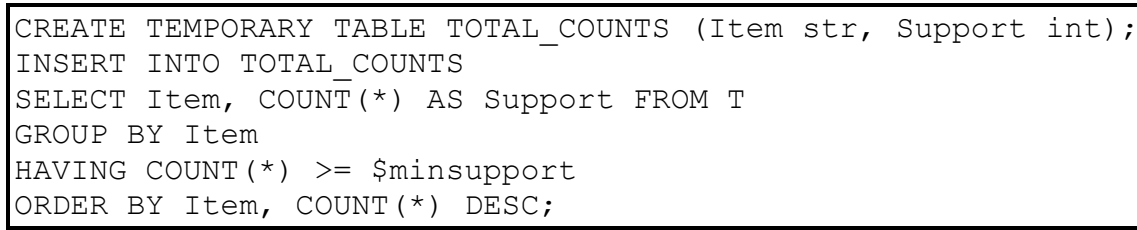


(2.) Transaction ordering (pengurutan transaksi): mengurutkan item-item frekuen dari tabel transaksi dalam urutan secara descending berdasarkan frekuensi kemunculan item tersebut.

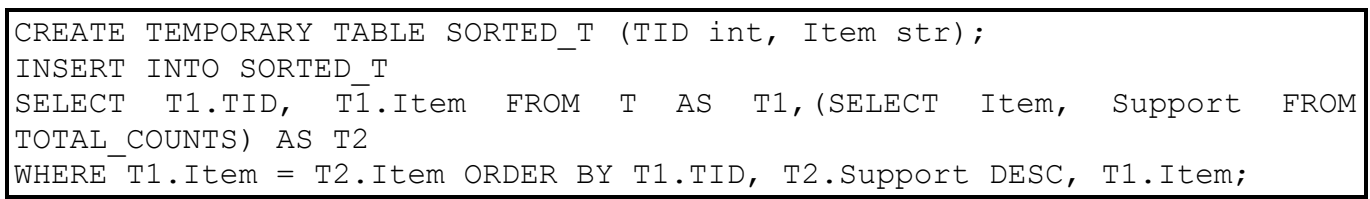

(3.) FP-Table construction (pembuatan tabel FP): membuat tabel FP yang memuat semua transaksi dengan item-item yang memenuhi batasan frekuensi kemunculan item (minimum support count).

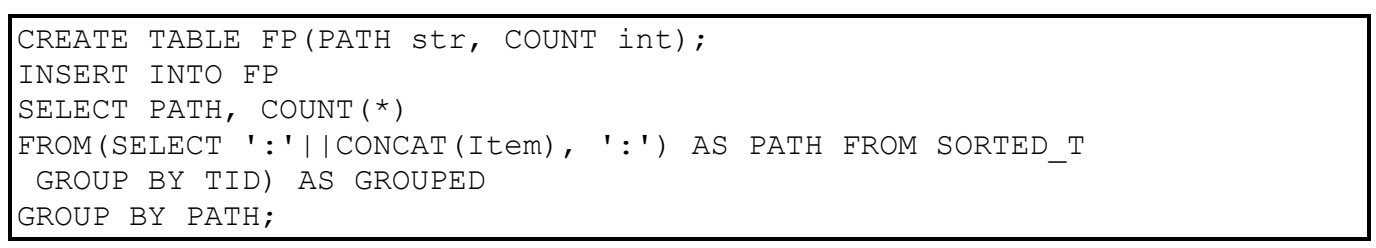

b. Menemukan Pola Frekuen dari Tabel FP

Setelah tabel FP selesai dibuat, langkah selanjutnya adalah membuat tabel conditional FP untuk setiap item sebelum menemukan semua pola frekuen dari tabel FP. Pembuatan tabel conditional FP dapat dikerjakan dengan mengeksekusi perintah SQL seperti berikut:

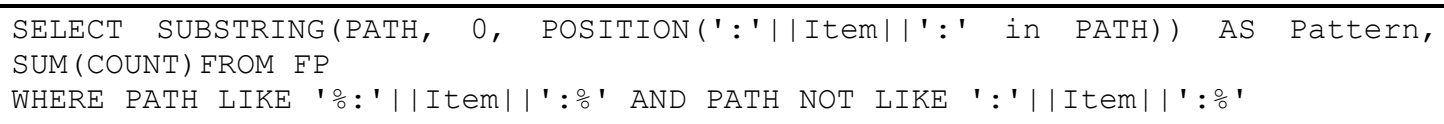

\section{Hasil dan Pembahasan}

Pengujian fungsi data mining dengan masukan (input) tahun data 2013 (tabel datakb2013) dan variasi nilai lift ratio. Cuplikan data pada tabel awal (datakb2013) dan tabel transaksi hasil transformasi dan integrasi dari tabel datakb2013 ditunjukkan pada tabel 1.

Tabel 1. Tabel data KB 2013

\begin{tabular}{|c|c|c|c|c|c|c|c|c|c|c|}
\hline id_kel id & suami & umur_s & pend_s & pek_s istri & umur_i & pend_i & pek_i & jml_anak & tk & mk \\
\hline 1001 & & 40 & B7 & E41 & 43 & B7 & D87 & 3 & $\mathrm{D} 2$ & 0 \\
\hline 1001 & & 33 & B1 & E19 & 27 & B2 & D01 & 2 & D0 & 1 \\
\hline 1001 & & 25 & B1 & E14 & 23 & B4 & D14 & 1 & D1 & 1 \\
\hline 1001 & & 35 & B1 & E14 & 38 & B4 & D14 & 2 & D1 & 1 \\
\hline 1001 & & 28 & B1 & E14 & 27 & $\mathrm{~B} 2$ & D01 & 2 & D0 & 1 \\
\hline 1001 & & 35 & B7 & E14 & 34 & B7 & D14 & 1 & D3 & 1 \\
\hline 1001 & & 32 & B7 & E14 & 31 & B4 & D14 & 2 & D1 & 3 \\
\hline 1001 & & 32 & B7 & E14 & 36 & B7 & D14 & 2 & $\mathrm{D} 2$ & 1 \\
\hline 1001 & & 57 & B7 & E14 & 51 & B7 & D04 & 4 & D4 & 4 \\
\hline 1001 & & 31 & B4 & E14 & 36 & B6 & D14 & 2 & $\mathrm{D} 2$ & 4 \\
\hline
\end{tabular}

Data pada tabel datakb2013 diseleksi dan ditransformasikan ke dalam format untuk analisis, kemudian diintegrasikan untuk mendapatkan tabel transaksi. Identifier (ID) transaksi adalah nomor kartu keluarga Pasangan Usia Subur (PUS) peserta KB.

Tabel 2. Tabel transaksi (kanan) hasil integrasi tabel hasil transformasi dari tabel datakb2013 (kiri)

\begin{tabular}{|c|c|c|c|c|c|c|c|c|c|}
\hline Id & umur_i & pend & jml_anak & tk & $\mathbf{m k}$ & id & antecedent & consequent & path \\
\hline & A2 & B4 & C3 & D2 & G0 & & A2:B4:C3:D2 & G0 & $\mathrm{A} 2: \mathrm{B} 4: \mathrm{C} 3: \mathrm{D} 2 \Rightarrow \mathrm{G} 0$ \\
\hline & A2 & B7 & $\mathrm{C} 0$ & D1 & G0 & & A2:B7:C0:D1 & G0 & $\mathrm{A} 2: \mathrm{B} 7: \mathrm{C} 0: \mathrm{D} 1=\mathrm{G} 0$ \\
\hline & A2 & B4 & $\mathrm{C} 2$ & D1 & G1 & & A2:B4:C2:D1 & G1 & A2:B4:C2:D1 => G1 \\
\hline & A2 & B6 & $\mathrm{C} 2$ & D4 & G4 & & A2:B6:C2:D4 & G4 & A2:B6:C2:D4 => G4 \\
\hline & $\mathrm{A} 2$ & B7 & $\mathrm{C} 2$ & D2 & G2 & & $\mathrm{A} 2: \mathrm{B} 7: \mathrm{C} 2: \mathrm{D} 2$ & G2 & $\mathrm{A} 2: \mathrm{B} 7: \mathrm{C} 2: \mathrm{D} 2=>\mathrm{G} 2$ \\
\hline
\end{tabular}




\begin{tabular}{|c|c|c|c|c|c|c|c|c|c|}
\hline Id & umur_i & pend & jml_anak & tk & mk & id & antecedent & consequent & path \\
\hline & A2 & B6 & $\mathrm{C} 1$ & $\mathrm{D} 2$ & G1 & & A2:B6:C1:D2 & G1 & A2:B6:C1:D2 => G1 \\
\hline & $\mathrm{A} 2$ & B7 & $\mathrm{C} 1$ & $\mathrm{D} 2$ & G0 & & A2:B7:C1:D2 & G0 & $\mathrm{A} 2: \mathrm{B} 7: \mathrm{C} 1: \mathrm{D} 2=>\mathrm{G} 0$ \\
\hline & A1 & B3 & $\mathrm{C} 2$ & D0 & G3 & & A1:B3:C2:D0 & G3 & A1:B3:C2:D0 => G3 \\
\hline & $\mathrm{A} 2$ & B4 & $\mathrm{C} 1$ & D1 & G3 & & A2:B4:C1:D1 & G3 & A2:B4:C1:D1 => G3 \\
\hline & $\mathrm{A} 2$ & B7 & $\mathrm{C} 2$ & $\mathrm{D} 2$ & $\mathrm{G} 2$ & & A2:B7:C2:D2 & G2 & $\mathrm{A} 2: \mathrm{B} 7: \mathrm{C} 2: \mathrm{D} 2=>\mathrm{G} 2$ \\
\hline
\end{tabular}

Nilai minimum lift ratio pada hasil pengujian 302 data PUS pada analisis data mining SIDAKadalah 0.57 sedangkan nilai maksimum lift ratio adalah 60.24. Variasi nilai lift ratio dalam pengujian ini adalah 1, 10, dan 20. Masukan minimum lift ratio senilai 1, menghasilkan 199 aturan asosiasi. Masukan minimum lift ratio senilai 10, menghasilkan 14 aturan asosiasi. Sedangkan dengan masukan minimumlift ratio senilai 20, menghasilkan 3 aturan asosiasi. Berikut akan dijelaskan perhitungan nilai support, confidence, dan lift ratio untuk rule ke-6 :

Jumlah transaksi tabel transaksi $\quad=302$

Pola (Path)

$=\mathrm{A} 3: \mathrm{B} 1: \mathrm{C} 5: \mathrm{D} 2 \Rightarrow \mathrm{G} 7$

Antecedent

$=\mathrm{A} 3: \mathrm{B} 1: \mathrm{C} 5: \mathrm{D} 2$

Consequent

$=\mathrm{G} 7$

Frekuensi kemunculan path $\quad=4$

Frekuensi kemunculan antecedent $\quad=8$

Frekuensi kemunculan consequent $=17$

Support $($ Path $)=\frac{\sum \text { transaksi mengandung Path }}{\sum \text { transaksi dalam tabel transaksi }} \times 100 \%=\frac{4}{302} \times 100 \%=1.32 \%$

Confidence $($ Path $)=\frac{\sum \text { transaksi mengandung Path }}{\sum \text { transaksi mengandung Antecedent }} \times 100 \%$

$$
=\frac{8}{13} \times 100 \%=0.6667 \times 100 \%=66.67 \%
$$

Benchmark confidence $=\frac{\sum \text { transaksi dengan item dalam } \text { Consequent }}{\sum \text { transaksi dalam tabel transaksi }}=\frac{17}{302}=0.056291$

Lift Ratio $=\frac{\text { confidence }}{\text { benchmark confidence }}=\frac{0.6667}{0.05629}=11.84$

Aturan asosiasi yang lain dihitung nilai support, confidence, dan lift rationya dengan cara yang sama menghasilkan nilai seperti ditunjukkan pada tabel 3.

Tabel 3. Hasil pengujian terhadap fungsi data mining

\begin{tabular}{|c|c|c|c|c|c|c|}
\hline No. & Min. Lift Ratio & Rule ke- & Aturan Asosiasi & Support & Confidence & Lift Ratio \\
\hline \multirow{14}{*}{1.} & \multirow{14}{*}{10} & 1 & A2:B1:C3:D3 => G7 & 0.33 & 100.00 & 17.76 \\
\hline & & 2 & A2:B1:C4:D2 => G7 & 0.33 & 100.00 & 17.76 \\
\hline & & 3 & $\mathrm{~A} 2: \mathrm{B} 4: \mathrm{C} 1: \mathrm{D} 3=\mathrm{G} 2$ & 0.33 & 100.00 & 15.90 \\
\hline & & 4 & A2:B4:C3:D2 => G6 & 0.33 & 33.33 & 20.08 \\
\hline & & 5 & A2:B7:C3:D1 => G7 & 0.33 & 100.00 & 17.76 \\
\hline & & 6 & A3:B1:C5:D2 => G7 & 1.32 & 66.67 & 11.84 \\
\hline & & 7 & A3:B3:C5:D3 => G7 & 0.33 & 100.00 & 17.76 \\
\hline & & 8 & $\mathrm{~A} 3: \mathrm{B} 4: \mathrm{C} 3: \mathrm{D} 3=>\mathrm{G} 6$ & 0.66 & 100.00 & 60.24 \\
\hline & & 9 & A3:B6:C3:D4 => G7 & 0.33 & 100.00 & 17.76 \\
\hline & & 10 & A3:B7:C3:D2 => G6 & 0.33 & 25.00 & 15.06 \\
\hline & & 11 & A3:B7:C3:D4 => G7 & 0.33 & 100.00 & 17.76 \\
\hline & & 12 & A3:B7:C4:D2 => G7 & 0.33 & 100.00 & 17.76 \\
\hline & & 13 & A3:B7:C5:D4 => G7 & 0.33 & 100.00 & 17.76 \\
\hline & & 14 & A3:B8:C2:D3 => G6 & 0.33 & 50.00 & 30.12 \\
\hline \multirow{3}{*}{3.} & \multirow{3}{*}{20} & 1 & A2:B4:C3:D2 => G6 & 0.33 & 33.33 & 20.08 \\
\hline & & 2 & $\mathrm{~A} 3: \mathrm{B} 4: \mathrm{C} 3: \mathrm{D} 3=>\mathrm{G} 6$ & 0.66 & 100.00 & 60.24 \\
\hline & & 3 & A3:B8:C2:D3 => G6 & 0.33 & 50.00 & 30.12 \\
\hline
\end{tabular}


Berdasarkan hasil pengujian fungsi data mining yang ditunjukkan pada tabel 1,didapatkan beberapa informasi dengan ukuran interestingness yang ditunjukkan dengan nilai lift ratio. Atribut yang digunakan adalah atribut umur istri (A), pendidikan tertinggi PUS (B), jumlah anak (C), tingkat kesejahteraan (D), dan metode kontrasepsi $(\mathrm{G})$. Contoh analisis terhadap hasil pengujian adalah sebagai berikut:

\section{a. Minimum lift ratio 1}

Hubungan asosiasi yang terbentuk dijelaskan sebagai berikut:

(1.) PUS dengan kriteria jumlah anak 0 ( $\mathrm{C} 0)$ cenderung untuk tidak menggunakan metode kontrasepsi (G0).

(2.) PUS dengan kriteria umur istri kurang dari 20 tahun (A1) dan jumlah anak 1 cenderung untuk menggunakan metode kontrasepsi Suntik (G3).

(3.) PUS dengan kriteria umur istri kurang dari 20 tahun (A1) dan jumlah anak 2 cenderung untuk menggunakan metode kontrasepsi Implant (G4).

(4.) PUS dengan kriteria umur istri 20 - 39 tahun adalah kelompok umur istri dengan pilihan penggunaan metode kontrasepsi yang paling bervariasi.

(5.) PUS dengan kriteria umur istri 20 - 39 tahun dengan jumlah anak 1 (C1) lebih cenderung menggunakan metode kontrasepsi jangka pendek (non-MKJP), yaitu Pill (G1), Kondom (G2), atau Suntik (G3).

(6.) PUS dengan kriteria umur istri 20 - 39 tahun dengan jumlah anak 2 (C2) atau 3 (C3) lebih cenderung menggunakan non-MKJP Implant (G4) dan MKJP MOW (G5).

(7.) PUS dengan kriteria umur istri 40 tahun atau lebih (A3) dan jumlah anak 1 (C1) cenderung menggunakan tidak menggunakan program $\mathrm{KB}(\mathrm{G} 0)$.

(8.) PUS dengan kriteria umur istri 40 tahun atau lebih (A3), dan jumlah anak 2 (C2), cenderung menggunakan non-MKJP, yaitu Pill (G1), Suntik (G3), dan Implant (G4).

(9.) PUS dengan kriteria umur istri 40 tahun atau lebih (A3) dengan jumlah anak 3 atau lebih, cenderung menggunakan MKJP, yaitu MOW (G5), MOP (G6), dan IUD (G7).

\section{b. Minimum lift ratio 10}

Hubungan asosiasi yang terbentuk dijelaskan sebagai berikut:

(1.) Metode kontrasepsi MOP cenderung digunakan oleh PUS dengan kriteria umur istri 40 tahun atau lebih (A3) dengan jumlah anak 2 atau lebih, tingkat pendidikan minimum SLTA/Sederajat (B4), dan tingkat kesejahteraan keluarga minimum tingkat II (D2).

(2.) PUS dengan kriteria umur istri 20 - 39 tahun (A2) atau lebih (A3) dan jumlah anak 3 (C3) atau lebih, cenderung menggunakan metode kontrasepsi MOW (G6) atau IUD (G7).

\section{c. Minimum lift ratio 20}

Hubungan asosiasi yang terbentuk menunjukkan bahwa metode kontrasepsi MOP cenderung digunakan oleh PUS dengan kriteria umur istri 40 tahun atau lebih (A3) dengan jumlah anak 2 atau lebih, tingkat pendidikan minimum SLTA/Sederajat (B4), dan tingkat kesejahteraan keluarga minimum tingkat II (D2).

Secara umum, jika mengacu pada perhitungan lift ratio tertinggi (yaitu 20), menggambarkan bahwa metode kontrasepsi yang popular adalah MOP dimana metode ini digunakan oleh pasangan usia subur dengan karakteristik sebagai berikut:

a) umur istri 40 tahun atau lebih

b) jumlah anak 2 atau lebih,

c) tingkat pendidikan minimum SLTA/Sederajat,

d) dan tingkat kesejahteraan keluarga minimum tingkat II. 


\section{Simpulan}

SIDAK dapat digunakan untuk membantu mempermudah dalam pelaporan, penyimpanan, dan pengelolaan data $\mathrm{KB}$ serta mendukung proses analisis penggunaan metode kontrasepsi menggunakan teknik data mining asosiasi menggunakan algoritma $S Q L$-Based FPGrowth.

Berdasarkan analisis hasil pengujian fungsi data mining dengan menggunakan algoritma SQL-Based FP-Growth terhadap sampel data KB tahun 2013, menghasilkan nilai support tertinggi $1.66 \%$, nilai confidence tertinggi $100 \%$, dan nilai lift ratio tertinggi 60.24 . Semakin tinggi nilai parameter yang digunakan dalam pemrosesan dengan algoritma SQL-Based FPGrowth, semakin sedikit aturan yang dihasilkan, semakin kuat hubungan asosiasi antar atribut dalam aturan yang terbentuk.

Saran untuk pengembangan atau penelitian lebih lanjut yaitu dapat dilakukan pengujian terhadap semua atribut yang mempengaruhi pemilihan metode kontrasepsi dengan algoritma SQL-Based FP-Growth per atribut dan kombinasi gabungannya.

\section{Daftar Pustaka}

Han, J., \& Kamber, M. (2006). Data Mining: Concepts and Techniques. San Fransisco: Morgan Kauffmann Publisher.

Kadir, A. (2003). Pengenalan Sistem Informasi. Yogyakarta: Andi Offset.

Kusrini, \& Luthfi, E. T. (2009). Algoritma Data Mining. Yogyakarta: ANDI.

Kusumaningrum, R. (-, - -). Faktor-faktor yang Mempengaruhi Pemilihan Jenis Kontrasepsi yang Digunakan pada Pasangan Usia Subur. Dipetik May 13, 2014, dari eprints.undip.ac.id: http://eprints.undip.ac.id/19194/1/Radita_Kusumaningrum.pdf

Nasution, S. L. (2011, - -). faktor-faktor yang Mempengaruhi Penggunaan MKJP di Enam Wilayah Indonesia. Dipetik May 12, 2014, dari www.bkkbn.go.id: http://www.bkkbn.go.id/litbang/pusna/Hasil\%20Penelitian/FAKTORFAKTOR\%20YANG\%20MEMPENGARUHI\%20PENGGUNAAN\%20MKJP\%20DI\%20ENA M\%20WILAYAH\%20INDONESIA.pdf

Santosa, B. (2007). Data Mining: Teknik Pemanfaatan Data untuk Keperluan Bisnis. Yogyakarta: Graha Ilmu.

Santosa, B. (2007). Data Mining: Teknik Pemanfaatan Data untuk Keperluan Bisnis (1 ed.). Yogyakarta: Graha Ilmu.

Schuiling, N. H. (2014, Agustus). Scalable Frequent Pattern Mining using Relational Databases. Dipetik September 20, 2015, dari http://dspace.library.uu.nl/bitstream/handle/1874/298560/Thesis.pdf?sequence $=2$

Shang, X. (2005, February 14). SQL Based Frequent Pattern Mining. Dipetik Mei 15, 2015, dari http://diglib.uni-magdeburg.de/Dissertationen/2005/xueshang.pdf

Yakub. (2012). Pengantar Sistem Informasi. Yogyakarta: Graha Ilmu. 